\title{
A EXTENSÃO E A PESQUISA NA FORMAÇÃO DOCENTE INCLUSIVA: UMA EXPERIÊNCIA DA UEG/CÂMPUS INHUMAS
}

\author{
Carla Salomé Margarida de Souza ${ }^{1}$ \\ https://orcid.org/0000-0002-3063-6785 \\ Marlene Barbosa de Freitas Reis ${ }^{2}$ \\ https://orcid.org/0000-0002-2213-7281
}

\begin{abstract}
Resumo: Este artigo objetiva compartilhar uma experiência de integração entre a extensão e a pesquisa universitária. Partimos da seguinte inquietação: de que forma, integrar projetos distintos, com o objetivo de aprimorar a formação docente numa perspectiva inclusiva? Nesse sentido, relatamos uma experiência exitosa na formação docente do estudante universitário ocorrida no ano de 2018, na UEG/Câmpus Inhumas, entre o projeto de pesquisa científica: "As Políticas de Diversidade e Inclusão no Ensino Superior: Educação Especial e Letramento Digital numa Perspectiva Inclusiva" e o projeto de extensão: "Acompanhamento Pedagógico de Crianças dos anos iniciais do Ensino Fundamental da Rede Pública Municipal". Os resultados demonstram que é possível formar docentes em perspectivas inclusivas, sobretudo, possibilitando a integração entre a extensão e pesquisa na academia, contribuindo para o fortalecimento do papel social da universidade para além dos muros da instituição.
\end{abstract}

Palavras-chave: Extensão. Pesquisa. Integração. Formação Docente Inclusiva.

1 Mestranda do Programa de Pós-Graduação Interdisciplinar em Educação, Linguagem e Tecnologias (PPG-IELT) da Universidade Estadual de Goiás/Câmpus Anápolis. Pedagoga. Especialista em Docência Universitária; em Educação para a Diversidade e Cidadania; em Libras e Neuropsicopedagogia. Docente titular da UEG/Câmpus Inhumas e da Secretaria de Educação do Estado de Goiás. E-mail: c.salome@hotmail.com.

2 Pós-Doutora em Gestão da Informação e Conhecimento pela Universidade do Porto, Portugal. Doutorado em Políticas Públicas, Estratégias e Desenvolvimento pela UFRJ. Pedagoga. Atualmente é professora titular da Universidade Estadual de Goiás (UEG). Docente permanente do Programa de Pós-Graduação Interdisciplinar em Educação, Linguagem e Tecnologias (PPG-IEL/UEG/Anápolis) e no curso de Pedagogia da UEG/Campus Inhumas. E-mail: marlenebfreis@hotmail.com. 


\title{
EXTENSION AND RESEARCH IN INCLUSIVE TEACHING TRAINING: AN EXPERIENCE OF UEG/CÂMPUS INHUMAS
}

\begin{abstract}
This article aims to share an experience of integration between extension and university research. We start from the following concern: in what way, to integrate different projects, with the objective of improving the teacher training in an inclusive perspective? In this sense, we report a successful experience in the teaching of the university student that took place in 2018, at UEG / Câmpus Inhumas, between the project of scientific research: "Policies of Diversity and Inclusion in Higher Education: Special Education and Digital Literacy in a Perspective Inclusive "and the extension project:" Pedagogical Accompaniment of Children in the initial years of Elementary School of the Municipal Public Network". The results demonstrate that it is possible to train teachers in inclusive perspectives, above all, allowing integration between extension and research in the academy, contributing to the strengthening of the social role of the university beyond the walls of the institution.
\end{abstract}

Keywords: Extension. Search. Integration. Inclusive Teacher Training.

\section{LA EXTENSIÓN Y LA INVESTIGACIÓN EN LA FORMACIÓN DOCENTE INCLUSIVA: UNA EXPERIENCIA DA UEG/CÁMPUS INHUMAS}

Resumen: Este artículo tiene como objetivo compartir una experiencia de integración entre la extensión y la investigación universitaria. Partimos de la siguiente inquietud: ¿de qué forma, integrar proyectos distintos, con el objetivo de perfeccionar la formación docente en una perspectiva inclusiva? En este sentido, relatamos una experiencia exitosa en la formación docente del estudiante universitario ocurrida en el año 2018, en la UEG / Câmpus Inhumas, entre el proyecto de investigación científica: "Las Políticas de Diversidad e Inclusión en la Enseñanza Superior: Educación Especial y Letramento Digital en una Perspectiva Inclusiva "y el proyecto de extensión:” Acompañamiento Pedagógico de Niños de los años iniciales de la Enseñanza Fundamental de la Red Pública Municipal». Los resultados demuestran que es posible formar docentes en perspectivas inclusivas, sobre todo, posibilitando la integración entre la extensión e investigación en la academia, contribuyendo al fortalecimiento del papel social de la universidad más allá de los muros de la institución.

Palabras clave: Extensión. Investigación. Integración. Formación Docente Inclusiva.

Submetido em: 02/10/2018

Aceito em: 28/10/2018

\section{INTRODUÇÃO}

A tarefa em integrar projetos não é tarefa fácil na vida do docente e do acadêmico, dadas às demandas acadêmicas de ambos. Por vezes a extensão tem se tornado um 'terreno' pouco valorizado, por exigir tempo e energia sem ter o mesmo peso e status da pesquisa nas universidades. Entretanto, é preciso 
retomar o papel da universidade para além dos muros da instituição e integrar pesquisas às ações reais dos grupos envolvidos.

Com base neste pressuposto, o presente texto enfatiza a necessidade de integrar ensino, pesquisa e extensão na formação docente do estudante universitário. Desse modo, socializamos um relato das experiências de integração ocorrida no ano de 2018, na UEG/Câmpus Inhumas, entre o Projeto de pesquisa científica: "As Políticas de Diversidade e Inclusão no Ensino Superior: Educação Especial e Letramento Digital numa Perspectiva Inclusiva" coordenado pela Professora Dr. ${ }^{\text {a }}$ Marlene Barbosa de Freitas Reis e o Projeto de extensão: "Acompanhamento pedagógico de crianças dos anos iniciais do ensino fundamental da rede pública municipal", coordenado pela Professora Carla Salomé Margarida de Souza.

Os projetos com objetivos distintos foram integrados e organizados de maneira a unir esforços e ações que pudessem contribuir para a melhoria do aprendizado mais efetivo dos graduandos, e ações reais, como formação de professores de escolas públicas participantes dos projetos. Conforme Reis (2017, p. 39), essa articulação é "fundamental para a democratização do conhecimento acadêmico, além de fortalecer o elo entre a universidade e a comunidade universitária e local, ressignificando as relações de parcerias e o cumprimento da função social da UEG”.

\section{INTEGRAÇÃO DE PROJETOS DE EXTENSÃO E PESQUISA NA FORMAÇÃO DOCENTE INCLUSIVA}

As atividades de pesquisa são indispensáveis aos professores universitários e acadêmicos, não somente como produção de conhecimento, mas também como formação continuada. A extensão deve ser entendida como extensão de pesquisa e ensino, não somente como prestação de serviço à comunidade para manutenção da mesma. Nesse sentido, ensino, pesquisa e extensão são atividades constitutivas do ensino superior e devem ser contempladas nos Projetos Político Pedagógicos dos cursos, norteadores dos trabalhos coletivos de formação (MARTINS, 2011).

O Projeto de Pesquisa: "As Políticas de Diversidade e Inclusão no Ensino Superior: Educação Especial e Letramento Digital numa Perspectiva Inclusiva" tem como eixo norteador promover uma discussão sobre os reflexos das 
políticas públicas "para e na" diversidade que são, ainda, um grande desafio para a educação brasileira, principalmente no tocante ao ensino superior. As discussões são abertas à toda comunidade universitária e local que se efetivam no Grupo de Estudos e Pesquisas em Educação, Diversidade e Inclusão (GEPEDI).

O GEPEDI foi instituído em 2015 e integra atualmente: 5(cinco) acadêmicas de Iniciação Científica do curso de Pedagogia do Câmpus Inhumas, 3 (três) acadêmicas de curso de pós-graduação PPG-IELT do Câmpus CCSEH de Anápolis; há que mencionar que as discussões no GEPEDI são públicas e, por isso, o perfil dos participantes e número de envolvidos varia a cada encontro. Pensar a pesquisa no mundo contemporâneo "significa pensar o papel do professor na perspectiva do aprender a aprender, pois dois elementos fundamentais da aprendizagem aí estão presentes: o ato da criatividade e a valorização da subjetividade"(DEMO, 1994, p. 15).

Em relação ao Projeto de Extensão "Acompanhamento pedagógico de crianças dos anos iniciais do ensino fundamental da rede pública de Inhumas" tem como principal objetivo, acompanhar e atender alunos dos anos iniciais do ensino fundamental que apresentam dificuldades de aprendizagem. O projeto atende 23 crianças de duas escolas municipais da cidade de Inhumas. É coordenado por uma participante permanente do GEPEDI e executado por 02(duas) bolsistas permanência, juntamente com a turma do $4^{\circ}$ período de Pedagogia da UEG/ Câmpus Inhumas.

O artigo $5^{\circ}$ do Plano Nacional de Extensão Universitária (2011, p. 5) traz como sendo uma das suas diretrizes o "engajamento da universidade com a sociedade, mediado por uma relação bidirecional de mútuo desenvolvimento". Fica entendido, que a extensão é o braço universitário que atua na comunidade, objetivando não somente impactá-la, mas também ser impactada com a vivência social, cultural e política, de modo que os benefícios dessa prática atinjam a todos os envolvidos.

A integração das ações dos projetos surgiu da necessidade de intensificar esforços no campo do ensino, da extensão e da pesquisa, no tocante a formação docente para perspectivas inclusivas. Assim, as principais ações foram: estudos sistematizados sobre textos relacionados à educação inclusiva; reuniões com professores da escola básica em conjunto com a universidade para diagnóstico dos principais problemas em relação ao aprendizado dos discentes que participam do projeto de extensão; organização de oficinas de trabalho 
junto aos professores da escola básica, com os graduandos de Pedagogia, e o GEPEDI, além da produção de material didático, utilizado nas oficinas.

A nossa grande preocupação, foi criar um espaço de estudo, reflexão e partilha para a busca de novos conhecimentos e alternativas pedagógicas para a melhoria do aprendizado dos alunos das duas escolas parceiras do projeto de extensão. Além disso, outro foco foi a busca pelo aprimoramento da formação continuada para docentes da educação básica e formação docente do estudante universitário do curso de Pedagogia, em uma perspectiva crítico-reflexiva, que forneça aos futuros pedagogos e pedagogas os meios de um pensamento autônomo e que facilite dinâmicas de autoformação participada.

Formar professores por meio de ações integradas entre pesquisa e extensão não é tarefa simplista. Requer grande esforço para compreensão das necessidades, dificuldades, limitações e significados atribuídos ao papel do professor. Para Nóvoa (1992, p. 14), “a formação não se constrói por acumulação (de cursos, de conhecimentos ou de técnicas), mas sim através de um trabalho de reflexividade crítica sobre as práticas e de (re)construção permanente de uma identidade pessoal." A intenção do caso aqui relatado, é trazer essa essência no processo de formação docente.

Desta forma, tanto a pesquisa, quanto a extensão são primordiais para adentrar no espaço da escola e intervir no mesmo, pois a escola não deve ser utilizada apenas como espaço de coleta de dados que na maioria das vezes não retornam para a própria instituição. Tomamos as palavras de Moita e Andrade como cruciais para o trabalho da universidade:

[...] insistimos que a extensão não seja tratada como uma tarefa compulsória, mas antes, à semelhança do que ocorre com a pesquisa, uma atividade que decorre naturalmente desse compromisso social de uma instituição orientada pela superação das distâncias entre o saber científico e popular. (MOITA; ANDRADE, 2009, p. 22)

Apoiando-nos nas ideias dos autores acima, concordamos que a extensão não pode ser considerada como trabalho de menor valor na universidade, mas estar integrada às ações de ensino e pesquisa. E nesse sentido, é preciso considerar que a extensão é um mecanismo da aprendizagem, por isso mesmo ligada, indissociavelmente, ao ensino e à pesquisa. (GOULART, 2004). 


\section{AS AÇÕES DE INTEGRAÇÃO}

Estudos sobre textos relacionados à educação inclusiva junto ao Grupo de Estudos e Pesquisas em Educação, Diversidade e Inclusão (GEPEDI) da UEG/ Câmpus Inhumas.

Em 2018, foram explorados 7(sete) textos, conforme demonstra o quadro abaixo.

QUADRO 01: TEXTOS ESTUDADOS NO GEPEDI 2018.

\begin{tabular}{|c|c|c|}
\hline ORD & TEXTOS & AUTOR/ANO \\
\hline $1^{\circ}$ & $\begin{array}{c}\text { Educação Inclusiva: será que sou a favor } \\
\text { ou contra uma escola de qualidade para } \\
\text { todos? }\end{array}$ & FERREIRA, Windyz Brazão/2005 \\
\hline $2^{0}$ & $\begin{array}{l}\text { Inclusão Escolar: Um Olhar Para a } \\
\text { Formação Docente e o Atendimento } \\
\text { Educacional Especializado (AEE). }\end{array}$ & $\begin{array}{c}\text { REIS, M. B. F.; SANTOS, T. P.; OLIVEIRA, B. } \\
\text { F.; TAVARES, A. R.; SILVA, B.T.; CAMPOS, } \\
\text { D.R.; LANZONI, T. S./2017. }\end{array}$ \\
\hline $3^{\circ}$ & $\begin{array}{c}\text { Educação inclusiva: do que estamos } \\
\text { falando? }\end{array}$ & CARVALHO, R. E./2005. \\
\hline $4^{\circ}$ & $\begin{array}{l}\text { A educação especial e a educação } \\
\text { inclusiva no cenário brasileiro; } \\
\text { contextualização do problema }\end{array}$ & DELOU, Cristina Maria Carvalho/2009. \\
\hline $5^{\circ}$ & $\begin{array}{l}\text { Educação Inclusiva: com os pingos nos } \\
\text { "is". }\end{array}$ & CARVALHO, Rosita Edler/2005. \\
\hline $6^{\circ}$ & $\begin{array}{l}\text { Educação Inclusiva: limites e } \\
\text { perspectivas. }\end{array}$ & REIS, Marlene Barbosa de Freitas/2006. \\
\hline $7^{\circ}$ & $\begin{array}{l}\text { Política Nacional de Educação Especial } \\
\text { na Perspectiva da Educação Inclusiva. }\end{array}$ & BRASIL/2008. \\
\hline
\end{tabular}

FONTE: AS AUTORAS/2018

As discussões decorrentes de todos os textos reforçaram a importância de se colocar em evidência a inclusão no processo escolar num viés para além da instrumentalização técnica. $\mathrm{O}$ foco se deu na percepção dos participantes e na relação de alteridade apontada pelos mesmos durante os encontros.

Reuniões com equipe gestora, professores e pais para avaliação do desenvolvimento dos acompanhamentos pedagógicos com as crianças.

Com o objetivo de avaliar o desenvolvimento do projeto de extensão, e compartilhar com a comunidade das escolas participantes, os resultados obtidos com esta parceria, realizamos dois encontros no Laboratório de Pedagogia, um em junho, outro em dezembro de 2018. Nesses encontros, após 
um momento de acolhida inicial, socializamos os portfólios fotográficos dos acompanhamentos com as crianças, e repassamos as fichas de registro individual do desenvolvimento de cada criança (Modelo quadro 02). A equipe gestora teve a oportunidade de verificar as atividades que foram desenvolvidas com as crianças e as percepções das monitoras acadêmicas que desenvolveram os acompanhamentos, ao registrar o desenvolvimento de cada criança.

QUADRO 02: FICHA DE RECISTRO INDIVIDUAL DO DESENVOLVIMENTO DE CADA CRIANÇA

\section{FICHA DE ACOMPANHAMENTO PEDACÓGICO}

Projeto de Extensão: Acompanhamento pedagógico de crianças dos anos iniciais do ensino fundamental da rede pública de Inhumas

Unidade Escolar: Escola Municipal Manoel da Silva Brandão

Município: Inhumas

Nome do aluno:

Idade:

Monitora:

Série/Ano: Agrupamento/dia: NEE: Meses:

Síntese dos acompanhamentos pedagógicos desenvolvidos?

\begin{tabular}{|l|l|l|l|l|} 
ASPECTOS ACADÊMICOS OBSERVADOS & INSUFICIENTE & REGULAR & BOM & ÓTIMO
\end{tabular}

Interação Afetiva e Social

Interesse nas atividades

Atenção

Concentração

Execução da atividade

Percepção de diferenças e semelhanças

Pontualidade

Frequência do aluno

Compreensão e atendimento a normas

Desenvolvimento de habilidades de vida

diária escolar

Organização do material pessoal

Habilidade sensório-motora

Percepção e memória visual

Percepção e memória auditiva

Orientação temporal 


\author{
Orientação espacial \\ Linguagem e comunicação oral \\ Linguagem e comunicação escrita \\ Raciocínio lógico-matemático \\ Expressão criativa
}

OBSERVAÇÕES:

Após o momento de diálogo sobre as fichas de acompanhamento, a equipe gestora, professores e pais, tiveram a oportunidade de avaliar a execução do projeto, por meio de uma ficha específica, em que cabe aqui, mencionar uma das falas de uma participante.

Agradecemos a UEG, pelo desenvolvimento do projeto de extensão na qual as crianças da nossa escola tiveram a oportunidade de participar. Foi de grande contribuição para a aprendizagem das crianças. Elas demonstraram melhorias em vários sentidos, desde ao cognitivo, amenizando dificuldades de raciocínio e leitura, a auto-estima e atenção. As crianças amam participar dos acompanhamentos e a cada dia que participam, chegam na escola contando novidades. Um projeto excelente! (COODENADORA PEDAGÓGICA DE UMA DAS ESCOLAS)

As acadêmicas que desenvolveram os acompanhamentos, também registraram a importância do projeto, conforme relataram:

É a primeira vez que participo de um projeto envolvendo crianças na UEG, foi bastante positivo, porque possibilitou a ligação da universidade com as escolas, unindo a teoria com a prática, contribuindo com a aprendizagem das crianças e com a nossa identidade de docente. (MONITORA A)

O projeto também nos proporciona amadurecer enquanto profissionais, uma vez que elaboramos planos com atividades lúdicas que engloba assuntos do dia a dia, conteúdos e principalmente atividades que supra as dificuldades das crianças com relação a leitura e escrita e raciocínio lógico matemático, e avaliamos, a avaliação e continua e prioriza a qualidade e o processo de aprendizado e não tem o intuito de classificar. Enfim o projeto traz novas possibilidades tanto para nós acadêmicas do curso de pedagogia, quanto para as crianças da comunidade. (MONITORA B). 
Percebemos que o projeto de extensão mencionado, tem sido muito importante porque contribui com a formação acadêmica das monitoras que desenvolvem os acompanhamentos com as crianças, possibilitando na prática, a vivência didática com crianças que apresentam dificuldades de aprendizagem, desenvolvendo metodologias que instigam o aluno a buscar o conhecimento de forma divertida e diferenciada. Além do mais, o projeto contribui de forma considerável com a aprendizagem e desenvolvimento das crianças acompanhadas.

\section{FORMAÇÃO DOCENTE NUMA PERSPECTIVA INCLUSIVA}

\section{Concepções teóricas}

Não podemos deixar de apresentar algumas concepções e princípios que norteiam a necessidade de uma formação docente inclusiva. Reis (2013) salienta que a formação inicial é um período onde o professor tem o contato com conhecimentos que provavelmente enfrentará na sua prática pedagógica. E acrescenta ainda que

[...] somente essa formação não será suficiente para o desenvolvimento de conhecimentos que garantam a efetividade de uma prática pedagógica que contemple princípios inclusivos. Tais conhecimentos para uma gestão inclusiva só poderão ser adquiridos por meio de uma prática continuada, reflexiva e coletiva (REIS, 2013, p.87).

Sabendo que a formação de professores é o ponto chave para o desenvolvimento de práticas bem sucedidas, Santos; Oliveira; Reis (2017, p.775), destacam que "[...] os próprios professores questionam a falta de preparo e de formação específica para lidar com o processo de inclusão escolar", o que nos leva a considerar também a importância da formação continuada oferecida pela universidade.

Para Jesus e Effgen (2012, p.17) “a formação continuada em processo tem se configurado como uma possibilidade de pensar as demandas escolares e os processos de escolarização dos sujeitos", visto que a formação continuada se torna fundamental para a atuação dos profissionais com todos os alunos.

Desse modo, a formação docente deve ter foco para trabalhar com novas estratégias para aprimorar o desenvolvimento dos alunos, pois de acordo com Fonseca e Carvalho (2012), a formação continuada e as mudanças na organização 
pedagógica da escola são as condições de fortalecimento dos espaços para a aprendizagem efetiva, e a construção do conhecimento. É necessário ainda que

[...] a formação do professor deve contemplar a valorização da diversidade, a construção de uma nova visão de educação, a flexibilização das práticas pedagógicas, a competência para trabalhar de forma colaborativa com outros profissionais e a habilidade de reconhecer as necessidades educativas de cada aluno (SANTOS; OLIVEIRA; REIS, 2017, p.775).

Certamente, a flexibilização das práticas pedagógicas e o trabalho em conjunto é de extrema importância, pois assim, as atividades que serão desenvolvidas com os alunos, poderão propiciar um suporte no que diz respeito ao desenvolvimento de todas as habilidades. E diante disso, para amenizar ainda mais os desafios, o professor deve ter uma postura de investigador, pesquisador crítico, pois somente assim poderá adquirir novos conhecimentos com base na sua própria realidade.

Paulo Freire destaca a importância de ensinar, de aprender e de pesquisar, pois o professor ao ensinar os conhecimentos já existentes, deve trabalhar na produção de conhecimentos ainda não existentes. Complementa ainda que "a prática docente crítica, implicante do pensar certo, envolve o movimento dinâmico, dialético, entre o fazer e o pensar sobre o fazer" (FREIRE, 2002, p.22).

Reforçamos as palavras de Nóvoa, ao pontuar que "a formação não se constrói por acumulação (de cursos, de conhecimentos ou de técnicas), mas sim através de um trabalho de reflexividade crítica sobre as práticas e de (re) construção permanente de uma identidade pessoal" (NÓVOA, 1992, p.13).

Assim, formação continuada pode ser considerada como um amadurecimento da prática profissional, pois ainda de acordo com Nóvoa (1992, p.20) "a formação contínua deve capitalizar as experiências inovadoras e as redes de trabalho que já existem no sistema educativo" sendo esse o momento em que o professor irá aprofundar-se em conhecimentos específicos, investindo em novos saberes para desenvolver melhores práticas educativas.

Nessa perspectiva, entendemos que o trabalho docente requer do professor um olhar para a diversidade presente na sala de aula, ou seja, um olhar amplo e atento para as especificidades de cada indivíduo. De acordo com Santos; Oliveira; Reis (2017, p.776), os professores "precisam perceber que respeitar as diferenças não significa pensar que todos são iguais, ao contrário, significa aceitar a singularidade de cada indivíduo, respeitando-o nas suas diferenças”. Assim, sabendo que cada indivíduo possui suas diferenças, o professor deve 
buscar aprimorar sua prática pedagógica para que todos tenham participação ativa e cooperativa no processo de ensino e aprendizagem.

Ao trabalhar junto às concepções da diversidade, Santos; Oliveira; Reis (2017) explica que o professor possui oportunidades de elaborar projetos que promovam e ampliem a aprendizagem de todos, sem possuir nenhuma descriminação. Desse modo, pode-se trabalhar e praticar a alteridade ${ }^{3}$ para que os discentes saibam valorizar e respeitar as diferenças dentro e fora da sala de aula.

A organização do tempo e do espaço para atender a demanda, no que diz respeito a diversidade, é outro aspecto importante que o professor deve ficar atento. Figueiredo (2011) caracteriza que

[...] o professor situa-se como mediador, considerando aspectos como: atenção às diferenças dos alunos; variação de papéis que o professor assume diferentes situações de aprendizagem; organização dos alunos de forma que possibilite interações em diferentes níveis, de acordo com os propósitos educativos (grupo-classe, grupos pequenos, grupos maiores, grupos fixos) (FIGUEIREDO, 2011, p.142).

É compreendendo essas diferenças, que o professor poderá efetivar sua prática pedagógica, de forma que abrangerá todos os indivíduos presentes na sala de aula, trabalhando em prol de uma formação que contemple a diversidade. E ao contemplar a diversidade, nos atentamos para a inclusão, que, segundo Reis (2006, p.41), consiste em

um único sistema educacional de qualidade para todos os alunos, com ou sem deficiência e com ou sem tipos de condição atípica. É a valorização do ser humano e aceitação das diferenças individuais como um atributo e não como um obstáculo e todas as pessoas devem ser incluídas, sem exceção, para que possam desenvolver-se e exercer plenamente sua cidadania.

Efetivamente, trata-se de um modelo educacional que inclua todos os sujeitos vítimas da exclusão, e que de fato, valorize as diferenças de todos. A inclusão nos espaços educativos se tornará um meio de oportunizar uma educação que trabalha a diversidade, desenvolvendo um pensamento de aceitação das diferenças. Nesse sentido, para Ferreira (2005, p.43), a "inclusão não se refere somente às crianças com deficiência e sim à todas as crianças, jovens e adultos que sofrem qualquer tipo de exclusão educacional".

3 Ato de se colocar no lugar do outro na relação interpessoal, com consideração, valorização, identificação e dialogar com esse outro (FURTADO, 2012). 
Diante das considerações apresentadas, o que se percebe é que a inclusão postula uma reorganização nos sistemas de ensino, no intuito de que todas as escolas se tornem inclusivas, um ambiente propício que vise o acolhimento de todos os indivíduos, sem qualquer distinção ou discriminação. De acordo com a Política Nacional de Educação Especial na Perspectiva da Educação Inclusiva (2008), todos os indivíduos possuem o direito à educação, para desenvolver de forma plena todas as habilidades e potencialidades.

Desse modo, a educação inclusiva deve perpassar as barreiras do preconceito, e oferecer uma educação de qualidade. Para que isso aconteça, é necessário que as práticas pedagógicas da escola sejam flexíveis de modo que atendam às necessidades dos alunos, e reconheçam que cada um possui um modo e um tempo diferente para aprender.

O ensinar de maneira democrática exige que o professor, juntamente com os demais agentes da escola, assuma uma postura de inclusão diante da realidade ao incluir todos os indivíduos no processo de formação, fazendo com que os mesmos participem ativamente das atividades escolares, sem que haja nenhuma forma de segregação. Frente a isso, o professor não deve rotular ou questionar as possibilidades de aprendizagem da criança, muito menos trabalhar atividades diferenciadas com os alunos que possuem alguma deficiência, pois, de acordo com Machado

[...] A deficiência de um aluno também não é motivo para que o professor deixe de proporcionar-lhe o melhor das práticas de ensino, e ainda, não justifica um ensino à parte, individualizado, com atividades que discriminam e que se dizem "adaptadas" às possibilidades de entendimento de alguns (MACHADO, 2011, p.72).

Nesse caso, se o professor acolher as crianças em sua sala de aula, mas trabalhar com elas atividades diferenciadas, ou não oferecer as mesmas oportunidades o mesmo estará exercendo uma falsa educação inclusiva, pois de nada adiantará se a criança continuar sendo segregada dentro da sala de aula. Em outras palavras, a criança ou o indivíduo, continuará sendo incluído apenas no espaço físico da escola, sem ter nenhum envolvimento com os demais alunos e sem uma participação ativa no processo de aprendizagem, o que consequentemente, ocasionará sua exclusão social fora da sala de aula.

Foi considerando a formação continuada um processo de amadurecimento da prática, que oferecemos aos professores da educação básica do município 
de Inhumas, oportunidades de uma formação específica que será apresentada nos próximos tópicos deste trabalho.

Organização de oficinas pedagógicas aos professores da escola básica, juntamente com o GEPEDI

No dia 20 de abril de 2018 oferecemos a 52 professores da educação básica do município de Inhumas Goiás, uma formação sobre a temática "Deficiência Intelectual e Aprendizagem".

A oficina visou responder a seguinte inquietação: como incluir o aluno com deficiência intelectual na escola regular, de forma a oferecer-lhes possibilidades de aprendizagem e desenvolvimento? Buscamos na ludicidade as hipóteses para essa questão, a partir de embasamento em Zapparoli (2014), Kishimoto (2008), Batista e Mantoan, (2007) e em Rizzini e Menezes (2010), que abordam a utilização de diferentes recursos lúdicos na prática pedagógica, abrangendo eixos indispensáveis ao desenvolvimento cognitivo, social, afetivo e psicomotor da criança.

Nesse sentido, o objetivo geral desse minicurso foi contribuir com a formação profissional numa abordagem crítico-reflexiva da atuação docente junto aos alunos com deficiência intelectual. Este se desdobrou em três momentos: i) problematização da atuação docente numa dimensão macro da educação e da diversidade, refletindo sobre o processo de inclusão e aprendizagem da criança com deficiência intelectual; ii) discussão do termo "Deficiência Intelectual" refletindo sobre a concepção e importância da ludicidade na prática pedagógica inclusiva da criança com deficiência intelectual e iii) socialização de práticas lúdicas inclusivas onde os participantes puderam experienciar estratégias de adaptação pedagógica com a utilização da ludicidade, evidenciando-a como ferramenta facilitadora do processo de ensino e aprendizagem das crianças com deficiência intelectual.

No dia 21 de setembro de 2018 oferecemos outro encontro de formação com o tema: "Jogos e brinquedos no processo de aprendizagem de crianças com déficit cognitivo, síndrome de down e TEA" e estiveram presentes, 42 professores da educação básica da rede municipal de Inhumas/Goiás. Essa formação, contou com dois momentos: o primeiro momento foi de elucidação dos conceitos e características das crianças com déficit cognitivo que possuem síndrome de down e transtorno do espectro autista (TEA) e no segundo momento, os participantes foram divididos em grupos para construção de um 
jogo ou brinquedo específico para atender as necessidades das crianças mencionadas. Após a construção do material, cada grupo, socializou a proposta de utilização, bem como as possibilidades de exploração, os objetivos e os materiais necessários para confeccionar tal jogo/brinquedo.

No dia 26 de novembro de 2018, oferecemos mais um encontro de formação docente, com a mesma temática anterior, porém para outro público, professores da educação infantil do município de Inhumas/Goiás. Participaram 69 professores. Assim como no encontro anterior, este também contou com dois momentos: de compreensão dos conceitos e características das crianças com déficit cognitivo que possuem síndrome de down e transtorno do espectro autista (TEA) e o segundo momento, onde os participantes também foram divididos em grupos para a construção de um jogo ou brinquedo específico para atender as necessidades das crianças mencionadas. Após a construção, cada grupo, socializou a proposta de utilização do material, bem como apresentou as possibilidades de exploração, os objetivos e os materiais necessários para confeccionar tal jogo/brinquedo.

Ao final, as oficinas foram avaliadas por meio de fichas construídas com base na escala likert, apresentando os seguintes descritores: fundamentos teóricos e didático-pedagógicos do curso; saberes construídos por intermédio do curso; metodologias utilizadas; desempenho das professoras; material audiovisual utilizado; realização do curso de forma geral. Os resultados foram compilados e estão identificados nos gráficos 01, 02 e 03.

GráfICO 01: AVALIAÇÃo DA OFICINA REALIZADA NO DIA 20 DE ABRIL DE 2018

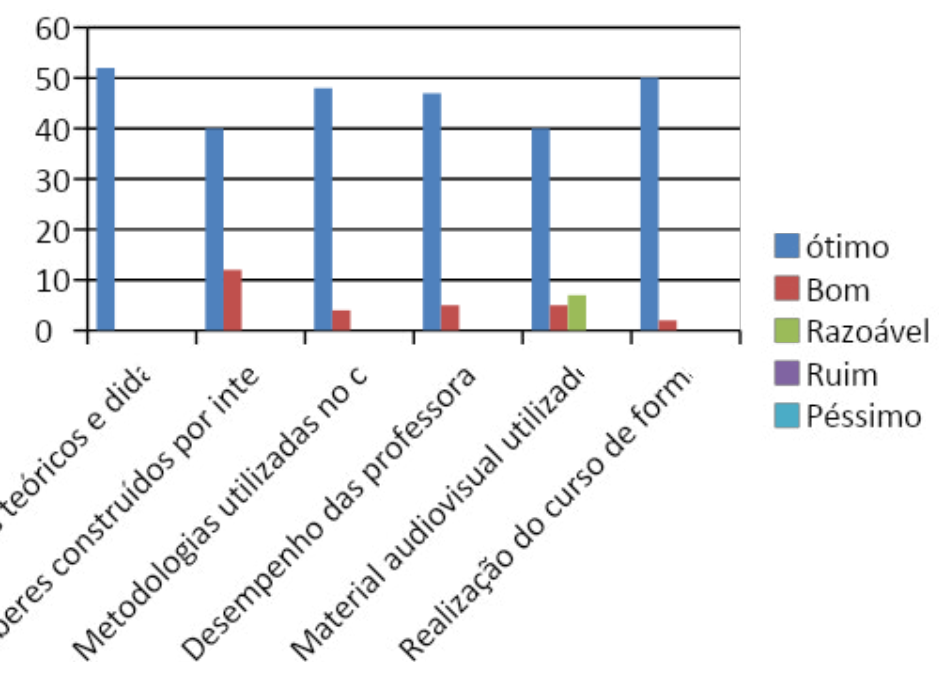

FONTE: OS AUTORES DO TEXTO COM BASE NAS INFORMAÇÕES DAS FICHAS DE AVALIAÇÃO DA OFICINA 
Gráfico 02: AVAliaÇÃo dA OfiCINA REALIZADA NO DIA 21 de SETEMBRO DE 2018
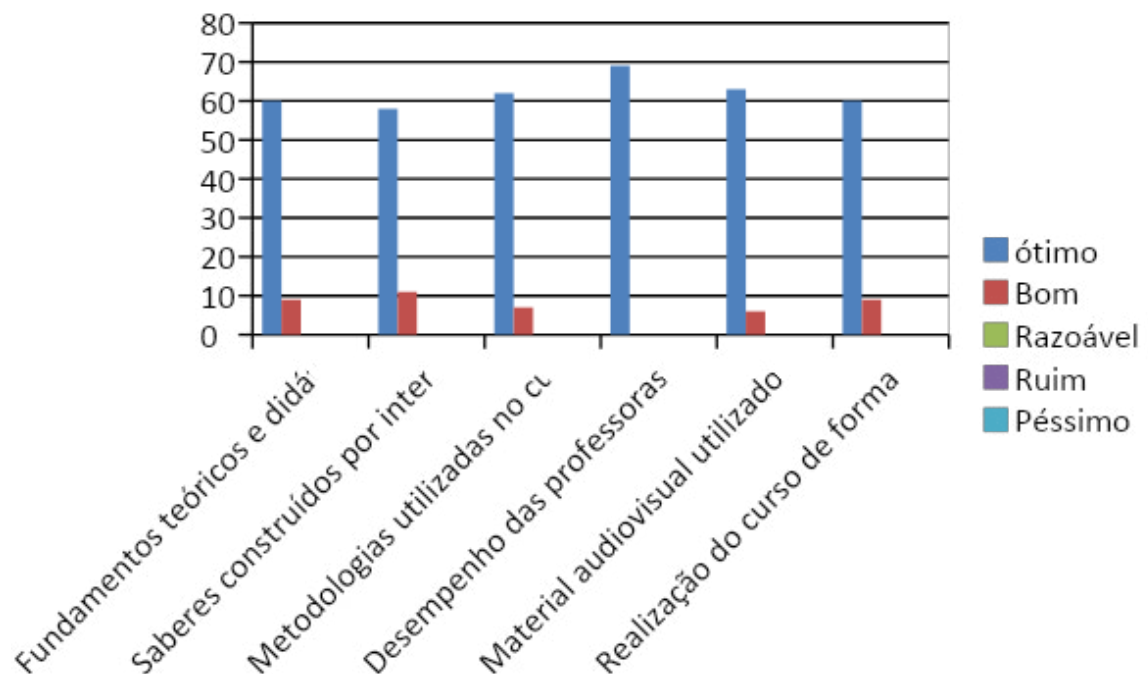

FONTE: OS AUTORES DO TEXTO COM BASE NAS INFORMAÇÕES DAS FICHAS DE AVALIAÇÃO DA OFICINA

GRÁFICO 03: AVALIAÇÃo dA OFICINA REALIZADA NO DIA 26 DE NOVEMBRO DE 2018

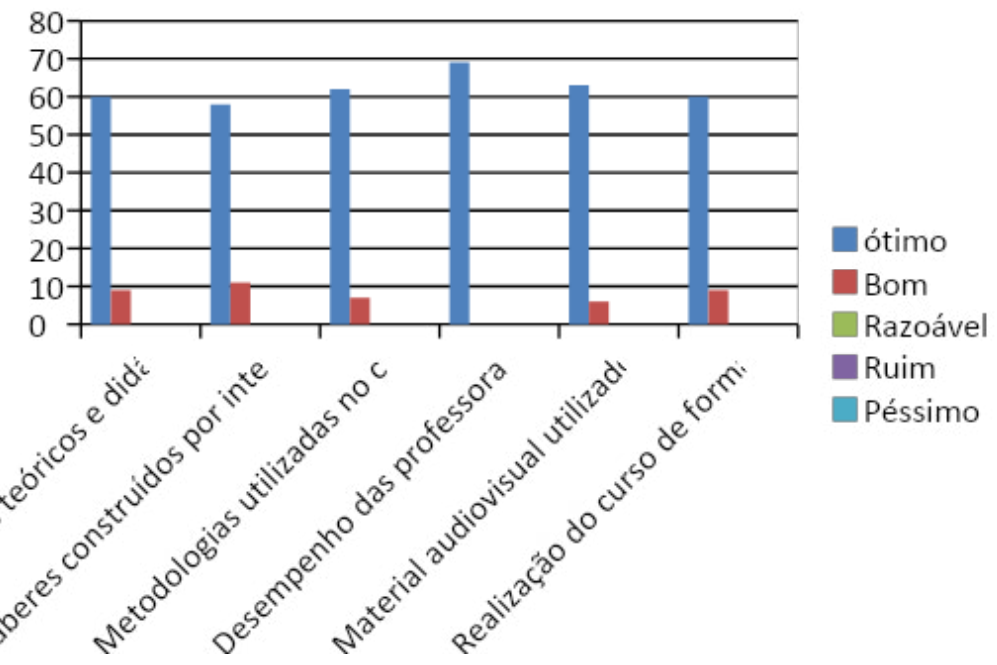

FONTE: OS AUTORES DO TEXTO COM BASE NAS INFORMAÇÕES DAS FICHAS DE AVALIAÇÃO DA OFICINA

Observa-se que os resultados foram satisfatórios em ambas as oficinas e que corresponderam às expectativas dos participantes e também os objetivos da formação docente numa perspectiva inclusiva.

Podemos dizer que a experiência de integração extensão/pesquisa, aqui apresentada, contribuiu com o fortalecimento da identidade da Universidade Estadual de Goiás/Câmpus Inhumas, em perspectivas inclusivas, vislumbrando caminhos para a educação com qualidade social. 
Percebemos também que os encontros de formação preencheram algumas lacunas na formação de professores que já atuam com crianças autistas e com síndrome de down, pois tiveram a oportunidade de entenderem a importância que as estratégias lúdicas assumem na aprendizagem destas crianças, conforme relata algumas professoras:

"A formação foi maravilhosa, aprendemos muito. Tivemos a oportunidade de refletir sobre a nossa atuação em sala de aula, de forma a perceber a relevância que a ludicidade assume na aprendizagem das crianças com deficiências" (DOCENTE, FORMAÇÃO 1).

"Foi ótimo a relação teoria e prática. Conhecemos muitos jogos e brinquedos acessíveis, de baixo custo e que podem ser confeccionados juntamente com as crianças. Jogos esses que atendem as necessidades específicas de crianças autistas e com TEA” (DOCENTE, FORMAÇÃO 2).

"Precisamos de mais formações como esta, que nos possibilitou entender a teoria e vivenciar a prática de forma bastante enriquecedora. Foi ótimo construir o brinquedo e compartilhar com todos" (DOCENTE, FORMAÇÃO 3).

Ao analisar a fala das professoras, percebemos o quanto a universidade pode contribuir com a formação continuada em perspectivas inclusivas.

\section{CONSIDERAÇÕES FINAIS}

Entendemos que o trabalho docente requer do professor um olhar para a diversidade presente em sala de aula, ou seja, um olhar amplo e atento para as especificidades de cada discente. Esse trabalho representa um grande desafio, principalmente para os docentes que não obtiveram uma formação específica na graduação. Por isso, a formação continuada, torna-se fundamental, e assim sendo, para cumprir seu papel social, a Universidade Estadual de Goiás, Câmpus Inhumas, procurou desenvolver ações com vistas a suprir as necessidades de formação dos professores de educação básica do município de Inhumas, além da formação inicial dos nossos futuros pedagogos e pedagogas. Portanto, surgiu a iniciativa de integrar a extensão e a pesquisa, através dos dois projetos mencionados neste texto.

Os projetos de extensão e pesquisa mencionados, com objetivos distintos, foram integrados e organizados de maneira a unir esforços e ações que pudessem contribuir para a melhoria do aprendizado mais efetivo dos graduandos, e a formação de professores de escolas públicas participantes dos projetos. 
Tanto as discussões, as reflexões e as atividades desenvolvidas na pesquisa, quanto as ações de extensão voltadas para a inclusão, vêm contribuindo, de forma significativa para o fortalecimento da formação de professores, no âmbito da UEG Câmpus Inhumas e no atendimento à comunidade externa.

\section{REFERÊNCIAS}

BRASIL. Ministério da Educação. Secretaria de Educação Especial. Política Nacional de Educação Especial na Perspectiva da Educação Inclusiva. Brasília: MEC/ SEESP, 2008. Disponível em: http://portal.mec.gov.br/index.php?option=com docman\&view=download\&alias=16690-politica-nacional-de-educacao-especial-na-perspectiva-da-educacao-inclusiva-05122014\&Itemid=30192. Acesso em: 05 dez. 2018. BRASIL. Plano Nacional de Extensão Universitária. Brasília, 2011. p. 1-5. Disponível em: http://pdi.ufabc.edu.br/wp-content/uploads/2011/09/Plano-Nacional-de-Extensão-Universitária-2011-2020.pdf. Acesso em: 20 dez. 2018.

DEMO, Pedro. Crise dos paradigmas na educação superior. Educação Brasileira, Brasília, v. 16, n. 32, p. 15-48, jan./jul. 1994.

FERREIRA, Windys B. Educação Inclusiva: será que sou a favor ou contra uma escola de qualidade para todos??? Inclusão: Revista da Educação Especial. Ministério da Educação. Out. 2005.

FIGUEIREDO, Rita Vieira de. A Formação de Professores para a Inclusão dos Alunos no Espaço Pedagógico da Diversidade. In. MANTOAN, Maria Teresa Eglér. (Org.). O Desafio das Diferenças nas Escolas. 4. ed. Petrópolis, RJ: Vozes, 2011. p. 141-145.

FONSECA, Rita de Cássia Oliveira da. CARVALHO, Carmen Silvia B. F. Formação de professores para o Atendimento educacional especializado: as propostas legais à prática cotidiana. In: JUNIOR, Manoel Osmar Seabra. CASTRO, Rosane Michelli de. (org.). Avaliação, Formação Docente e Perspectivas da Educação Inclusiva: eixos do atendimento educacional especializado. Oficina Universitária; São Paulo: Cultura Acadêmica, 2012, p, 101-113.

FREIRE, Paulo. Pedagogia da Autonomia: saberes necessários à prática educativa. São Paulo. 1996/2002.

FURTADO, Júlio. Docência e alteridade. Congresso de Educação Básica: aprendizagem e currículo: COEB, 2012.

GOULART, Audemaro Taranto. A importância da pesquisa e da extensão naformação do estudante universitário e no desenvolvimento de sua visão crítica. Revista Horizonte, Belo Horizonte, v. 2, n. 4, p. 60-73, $1^{\circ}$ sem. 2004. Disponível em: http://periodicos.pucminas.br/index.php/horizonte/article/view/580. Acesso em: 20 dez. 2018. 
JESUS, Denise Meyrelles de. EFFGEN, Ariadna Pereira Siqueira. Formação docente e práticas pedagógicas: conexões, possibilidades e tensões. In: MIRANDA, Theresinha Guimarães. FILHO, Teófilo Alves Galvão (org.). O professor e a Educação inclusiva: formação, práticas e lugares. EDUFBA. Salvador, 2012, p. 17-24.

MACHADO, Rosângela. Educação Inclusiva: revisar e refazer a cultura escolar. In. MANTOAN, Maria Teresa Eglér. (org.). O Desafio das Diferenças nas Escolas. 4 ed. Petrópolis, RJ: Vozes, 2011, p. 69-75.

MARTINS, Ligia. Ensino, pesquisa e extensão como fundamento metodológico na construção do conhecimento universitário. Disponível em: http://www.umcpos.com. br/centraldoaluno/arquivos/07_03_2014_218/2_-ensino_pesquisa_extensao.pdf. Acesso em: 19 dez. 2018.

MOITA, Filomena M. G. S. C. e ANDRADE, F. C. B. Ensino-pesquisa-extensão: um exercício de indissociabilidade na pós-graduação. Revista Brasileira de Educação v. 14 n. 41 maio/ago. 2009. Disponível em: http://www.scielo.br/pdf/rbedu/v14n41/v14n41a06. pdf. Acesso em: 18 dez. 2018.

NÓVOA, António S. O passado e o presente dos professores. In: NÓVOA, António S.(Org.). Profissão Professor. 2 ed. Porto: Porto Editora, 1992.

REIS, Marlene Barbosa de Freitas. Política pública, diversidade e formação docente: uma interface possível. Rio de Janeiro, 2013.

REIS, Marlene Barbosa de Freitas. Educação inclusiva: limites e perspectivas. Goiânia: Deescubra, 2006.

REIS, Marlene Barbosa de Freitas. A pesquisa como eixo articulador de conhecimentos. UEG VIVA, Revista da Universidade Estadual de Goiás, ano 4. N. 3, Anápolis, 2017. Disponível em: www.ueg.br/exec/revista/?funcao=tela_inicial. Acesso em: 15 dez. 2018. SANTOS, Thiffanne Pereira dos; OLIVEIRA, Brenda Fonseca de; REIS, Marlene Barbosa de Freitas. O Professor no Processo de Inclusão Escolar: possibilidade e desafios. In: VI SEMANA DE INTEGRAÇÃO. 6. 2017, Inhumas. Anais da VI Semana de Integração. Inhumas: UEG, 2017, p. 773-783. Disponível em: $<$ http://www.anais.ueg.br/index.php/ semintegracao/article/view/9000/6994>. Acesso em 13/mar./2018. 